Journal of Accident and Emergency Medicine 1995

$12,182-186$
Correspondence: T.F. Beattie Consultant, Accident and Emergency Department, Royal Hospital for Sick Children, 9 Sciennes Road, Edinburgh, EH9 9LF, UK

\title{
Intussusception presenting to a paediatric accident and emergency department
}

\author{
I.A.R. MACDONALD \& T.F. BEATTIE
}

Royal Hospital for Sick Children, Sciennes Road, Edinburgh, EH9 9LF

\section{SUMMARY}

In a retrospective study, 110 patients episodes with intussusception presenting to a paediatric accident and emergency (A\&E) department were reviewed, with particular attention being paid to presenting symptoms, time to diagnosis, radiological investigation, management and outcome. Between 1983 and 1993100 patients presented to this department with 110 episodes of intussusception. Delay in diagnosis of greater than $12 \mathrm{~h}$ from initial medical contact was associated with increased morbidity. Associated factors in delayed diagnosis were departure from the classical symptoms (pain, vomiting and blood per rectum) and the presence of diarrhoea. General practitioner (GP) referral was to the medical team (rather than the surgical team) in around $50 \%$ of cases. Irrespective of the specialty of the first hospital doctor to see the patient only $42 \%$ were diagnosed correctly within $3 \mathrm{~h}$ of admission. In this population diarrhoea is a common symptom of intussusception and should alert the clinician rather than reassure. Because of its many presentations and relative rarity, intussusception remains a difficult condition to diagnose.

Keywords: abdominal pain, acute abdomen, diarrhoea intussusception.

\section{INTRODUCTION}

Intussusception is one of the commonest causes of abdominal emergency in early childhood, although the average GP may only see two cases in a working lifetime. ${ }^{1}$ The mortality from the condition has been reduced in recent years and refinement of nonsurgical methods of treatment has reduced the number of cases requiring operative reduction. ${ }^{1-5}$ However a significant morbidity and mortality exists ${ }^{2}$. Several studies have shown delay in diagnosis increases morbidity and in particular reduces the success rate of non-surgical methods of reduction. ${ }^{2.5-7}$ Because it is relatively uncommon, the opportunity for first and second doctors to see a given case of intussusception is likely to be rare. In this paper we document the last 10 years experience of this condition as it has presented to a specialist paediatric A\&E department.

\section{SUBJECTS AND METHODS}

Using the International Classification of Disease Codes ICD(9) 543.0 and 560.0 all episodes of intussusception presenting to this hospital between 1983 and 1993 were identified. Those who were referred directly to surgical wards were not included in this paper but data are available for these patients. Data were obtained from case notes regarding demographic features, clinical presentation, timing of medical contact, time to diagnosis and details of management and outcome. Factors associated with late diagnosis were identified. The following definitions were used.

(1) Main symptoms at onset: the first description by the parent of the child's problem.

(2) Symptoms and signs at presentation: list of al factors detected and documented by the first doctor of whatever specialty or grade to see the patient.

(3) Symptoms and signs at diagnosis: list of all the factors detected and documented by the doctor of whatever specialty or grade to make the diagnosis.

(4) Pain: considered to be present if parents described the child as being in pain or screaming or if these terms were used by the attending medical staff.

(5) Because of the retrospective nature of the study we had to take clinicians descriptions as valid. 'Shocked', 'dehydrated', 'in pain', were frequently mentioned often without documenting supporting clinical evidence. Where possible these were verified by searching for collaborating signs. 
Intussusception

presenting to a

paediatric A\&E

department

\section{RESULTS}

A total of 123 episodes of patients with intussusception were identified. Eleven patient in this group bypassed the A\&E department. Of the remaining 112 patients, two sets of notes were unavailable leaving 110 for study.

\section{EPIDEMIOLOGICAL FEATURES}

The mean age of patients was 13 months with a range of 1 month to 11 years (Table 1). Eighty per cent of cases occurred in the first year of life. The modal age was 5 months. There were 72 males and $37 \mathrm{fe}-$ males giving a sex ratio of 2:1 male to female. There was a seasonal variation, most cases (16) occurring in September but this failed to reach statistical significance. An average of 10 cases occurred annually, $80 \%$ of which were in the first year of life. There was a cluster of nine patients presenting in the last 6 weeks of 1989 but this was exceptional.

The average birth rate for the catchment population during the study was 9000 per annum. Combining this with the first year of life incidence gives an incidence of intussusception in Lothian on the basis of this study of just under 1 per 1000 in the first year of life.

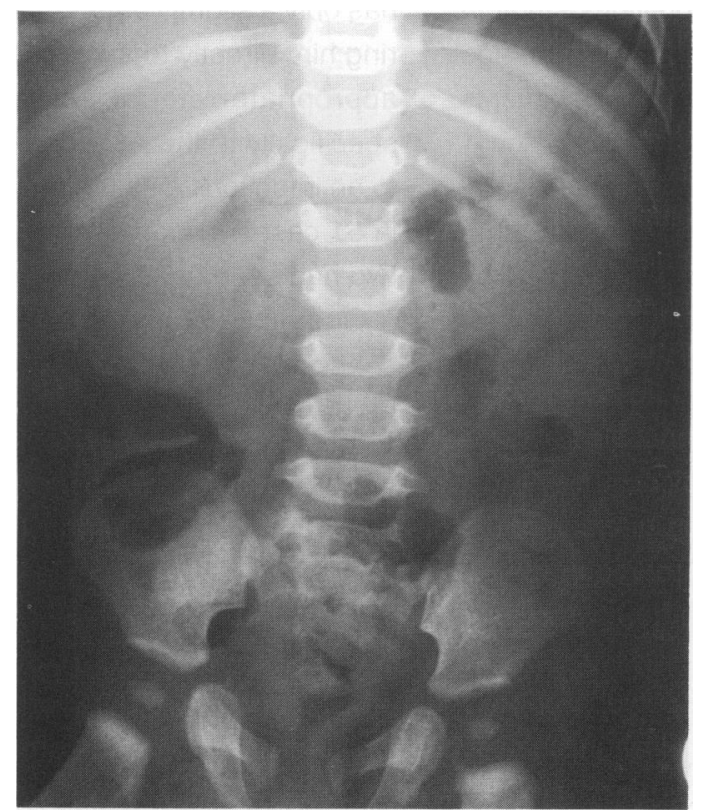

Fig. 1. A plain abdominal radiograph showing characteristic lack of gas in the right upper quadrant and soft tissue shadow in transverse colon corresponding to the intussusception.
PRESENTING SYMPTOMS AND SIGNS

This was analysed in the following way: the main symptom at onset was recorded and symptoms and signs at first presentation to a doctor and at diagnosis were noted. See Tables 1-3.

The main symptom at onset was pain in 53 patients and vomiting in 38 . A mass was present in 18 patients at presentation and in 53 patients at diagnosis. Thirty-four patients were described as being shocked or dehydrated.

\section{PRECEDING ILLNESSES}

These are listed in Table 4. The majority of children (93) did not have a recorded preceding illness.

\section{INVESTIGATIONS}

Abdominal radiographs were seen by the admitting clinicians prior to diagnosis in 56 patients. Radiographs were considered contributory to the diagnosis in 37 cases and abnormal in 49 cases by the admitting clinicians. A further 20 plain radiographs were ordered after admission. When subsequently reported by a radiologist, out of a total of 76 abdominal radiographs recorded, 51 were suggestive of intussusception and a total of 57 were reported as abnormal.

\section{DIAGNOSIS AND DISPOSAL}

Seventy-nine patients were diagnosed before leaving the A\&E department. Sixty-eight of these patients had the diagnosis made on the basis of symptoms and signs. Eleven were diagnosed solely on the basis of abdominal radiograph. Twenty-three of the 79 patients had arrived with a provisional diagnosis of intussusception; 16 were referred directly by their GP and seven were referred from other hospitals, e.g. the infectious disease unit, Borders or Fife. While ultrasound (USS) confirmed the diagnosis in many of these cases intussusception was the working diagnosis before USS was requested.

Seventy-nine patients were admitted to a surgical department after early reduction by surgical or radiological methods. Twenty patients were admitted to a medical ward, one was sent to an infectious disease unit and 10 were admitted to a surgical ward undiagnosed.

There were 30 cases where diagnosis was delayed $6 \mathrm{~h}$ or more after arrival at this hospital. 
I.A.R. Macdonald \& T.F. Beattie
Table 1.

\begin{tabular}{lc}
\hline Symptoms & No. of patients (\%) \\
\hline Pain & $53(48 \%)$ \\
Vomiting & $37(34 \%)$ \\
Diarrhoea & $8(7 \%)$ \\
Non-specific illness & $8(7 \%)$ \\
Bloody stool & $2(2 \%)$ \\
Apnoea & $1(1 \%)$ \\
No symptoms & $1(1 \%)$ \\
\hline
\end{tabular}

\section{DISCUSSION}

In the United Kingdom between one and two infants in every thousand will have an intussusception before their first birthday. ${ }^{1}$ The prognosis for most of these is good. Nonetheless, a review of childhood deaths from intussusception in England and Wales between 1984 and 1989 found 33 cases with a fatal outcome. Potentially avoidable factors contributing to death were excessive delay in diagnosis, inadequate intravenous fluid and antibiotic therapy, delay in recognizing recurrent or residual intussusception following hydrostatic reduction, and surgical complications ${ }^{2}$.

\section{EPIDEMIOLOGY}

The sex ratio of 2:1, male to female was similar to most other studies but differed from the previous study in this hospital which had shown a ratio of $1: 1$. The age range in this study was fairly narrow; $95 \%$ of patients were below the age of 3 years and $79 \%$ were below 1 year of age, unlike studies from Africa ${ }^{8}$ and Holland. ${ }^{9}$ In keeping with this homogeneity there were few pathological causes, only two cases being caused by Meckel's diverticulum (a rate not dissimilar to that for Meckels in the general population). The lack of significant seasonal variation was consistent with the last study from Edinburgh. ${ }^{4}$ The rate has risen from seven to 10 cases per year. The percentage of patients with a preceding infection stands constant at $15 \%$.

\section{CLINICAL FINDINGS}

At the time of presentation to a doctor, whether GP or hospital staff, only $33 \%$ of patients exhibited three or more of the classical features of pain, vomiting, bloody stool and abdominal mass. This rose to $64 \%$ at the time of diagnosis.

The most common main presenting complaint was vomiting, closely followed by pain, as in other studies. Diarrhoea was a common symptom, but we were unable to determine how much of this was infective and how much was a result of the intussusception itself. Diarrhoea resulted in a number of referrals to the infectious disease unit.

In an important minority (6\%) none of the classical symptoms were seen at first presentation. Clinical features at the time of diagnosis were not significantly different from other studies, with the exception of diarrhoea which was more common than in most. There were no cases of Henoch Schönlein purpura.

\section{DIAGNOSIS}

One of the problems in early diagnosis of this condition is that the first doctor to see the patient (GP in at least $90 \%$ of cases in this series), is very likely to decide that the child requires hospital care, but has only a slightly better than evens chance of referring him directly to a surgical unit. The GP made an appropriate referral for surgical opinion or nonspecifically to the A\&E department in 42 cases and to an infectious disease unit or for a medical opinion in 51 cases. There were five self-referrals, of whom two had seen a GP before.

Once in A\&E the department there was a $75 \%$ chance of patients being diagnosed correctly before further transfer/referral.

As might be expected there was a higher rate of

\begin{tabular}{lcccc}
\hline Symptom or sign & $\begin{array}{c}\text { At first } \\
\text { Presentation }\end{array}$ & $(\%)$ & $\begin{array}{c}\text { At time of } \\
\text { diagnosis }\end{array}$ & $(\%)$ \\
\hline Vomiting & 91 & $(83)$ & 97 & $(88)$ \\
Bile vomiting & 30 & $(27)$ & 43 & $(39)$ \\
Pain & 83 & $(75)$ & 88 & $(80)$ \\
Bloody stool & 35 & $(32)$ & 62 & $(56)$ \\
Mass & 18 & $(16)$ & 53 & $(48)$ \\
Diarrhoea & 35 & $(32)$ & 38 & $(35)$ \\
Shock/dehydration & 29 & $(26)$ & 34 & $(31)$ \\
\hline
\end{tabular}

Table 2. Frequency of common symptoms and signs present at presentation and at diagnosis 
Intussusception

presenting to a

paediatric A\&E

department
Table 3. Frequency of the classical features: pain, vomiting, bloody stool and abdominal mass

\begin{tabular}{lrl} 
No of cases with 3 or more symptoms & 33 & $(30 \%)$ \\
No of cases with 2 & 53 & $(48 \%)$ \\
No of cases with 1 & 19 & $(17 \%)$ \\
No of cases with none & 5 & $(5 \%)$ \\
\hline
\end{tabular}

Table 4. Number of patients with various preceding illnesses

\begin{tabular}{lrl}
\hline Upper respiratory tract infection & 11 & $(10 \%)$ \\
Proven gastro-enteritis & 2 & $(1.8 \%)$ \\
Urinary tract infection & 1 & $(0.9 \%)$ \\
Other cause of pyrexia & 4 & $(3.6 \%)$ \\
Total & 17 & $(15.5 \%)$ \\
\hline
\end{tabular}

early diagnosis in those children with the most classical symptoms. The presence of diarrhoea as an initial symptom delayed diagnosis irrespective of other symptoms or signs that were present. Although the difference was small, a patient was more likely to receive appropriate management within $3 \mathrm{~h}$ of admission if seen by a surgical member of staff. Accurate diagnosis by a GP was associated with least delay and this was the only group who had a better outcome from air/barium enema with $90 \%$ success rates. This group had the highest number with three or more classical signs.

Radiographs were taken before diagnosis in a number of cases (56). In most cases these were subsequently reported as abnormal but not necessarily diagnostic of intussusception. It was clear that an ultrasound scan performed on all abnormal radiographs would have resulted in an earlier diagnosis in 13 cases.

Other factors influencing time to diagnosis have been noted. Ways in which these may be modified are as follows.

In any child in the 'at risk' age group (i.e. under 3 years) who merits an abdominal radiograph, an expert radiological opinion should be sought. Alternatively, and possibly more fruitfully, both medical and surgical junior staff should be coached on the radiology of the acute abdomen. If any child in this age group has an unexplained abnormal abdominal radiograph, radiological opinion regarding the merit of ultrasound should be obtained (see Fig. 1).

In the 'at risk' age group the presence of diarrhoea should lead to consideration of intussusception. It has been said that the diarrhoea of intussusception is minimal and short-lived. This may be the case but it is apparent in this study that it can be sufficient to direct the patient to an infectious disease unit quite easily. It is clearly unrealistic and unhealthy to take a radiograph in each patient with diarrhoea, but an awareness and readiness to act if further classical symptoms appear would increase pick up rate. Diarrhoea which has ceased, allied with a child whose condition is not improving is probably quite an important symptom.

Many children were also shocked or dehydrated on presentation. In such children resuscitation in the form of intravenous fluid, plasma or normal saline, $10-20 \mathrm{~mL} \mathrm{~kg}^{-1}$ and opiate should be considered prior to radiology/ultrasound and radiological reduction where feasible.

Studies have shown duration of symptoms for longer than $24 \mathrm{~h}$ is associated with a lower likelihood of successful non-surgical reduction..$^{2.5-7}$ All modes of therapy have a better outcome in the hands of experienced staff. ${ }^{3.5}$ It is agreed that an improvement in the management of the condition will come from a wider appreciation of its varied presentation, prompt and aggressive resuscitation followed quickly by treatment in a centre with appropriate expertise. ${ }^{1-3}$

In conclusion increased awareness of the various possible presentations, and relevant investigation at an early stage should reduce the number of children who go down an inappropriate diagnostic route, i.e. to an infectious disease unit or medical ward. Early diagnosis leads to reduced surgical morbidity. Avoidance of excessive delay in diagnosis allied with appropriate resuscitation can help prevent mortality.

\section{ACKNOWLEDGEMENTS}

Thanks are due to the secretarial staff and records staff at Lothian Health Board for their invaluable help in tracing the case notes and to Elaine Lord for preparing the manuscript. Many of these patients were admitted under the care of paediatric surgeons, past and present, at the Royal Hospital for Sick Children in Edinburgh. We wish to express our thanks for allowing us to report on these patients.

\section{REFERENCES}

1. Stringer M.D.,Pledger S. \& Drake D.P. (1992) Childhood Deaths from Intussusception in England and Wales 1984-1989. British Medical Journal 304, 737-739.

2. Tangy V.T., Bear J.W., Reid I.S. \& Wright J.E. (1988) Intussusception in Newcastle in a 25 year period. Aus- 
I.A.R. Macdonald \&

T.F. Beattie tralia and New Zealand Journal of Surgery 58, 899-902.

3. Stringer M.D., Pablot S.M. \& Brereton R.J. (1992) Paediatric intussusception (Review). British Journal of Surgery 79, 867-876.

4. Wilson-Storey D., MacKinlay G.A., Prescott S. \& Hendry G.M.A. (1988) Intussusception: a surgical condition. Journal of the Royal College of Edinburgh 33, 270-273.

5. McDermott V.G., Taylor T., MacKenzie S. \& Hendry M.A. (1994) Pneumatic reduction of intussusception: clinical experience and factors affecting outcome. Clinical Radiology 49, 30-34.

6. Beasley S.W., Auldist A.W. \& Stokes K.B. (1988) The diagnostically difficult intussusception: it's characteris- tics and consequences. Paediatric Surgery International 3, 135-138.

7. Katz M., Phelan E., Carlin J.B. \& Beasley S.W. (1993) Gas enema for the reduction of intussusception: relationship between clinical signs and symptoms and outcome. American Journal of Roentgenology 160, 363-366.

8. Mamoh J.T. \& Lawrie (1981): Tropical paediatric intussusception - is it a different disease entity? Annals of Tropical Paediatrics 1, 237-240.

9. Reijnen J.A.M., Festen C., Joosten H.J.M. \& Van Weiringen P.M.V. (1999) Atypical characteristics of a group of children with intussusception. Acta Paediatrica Scandinavica 79, 675-679. 